\title{
Pitting Corrosion on Diamond-like Carbon Films in High Concentration Sodium Hydroxide Solutions
}

\author{
Hiroki Akasaka, Jumpei Nishikawa, and Naoto Ohtake \\ Department of Mechanical Engineering, School of Engineering, Tokyo Institute of Technology, \\ 2-12-1 Ookayama, Meguro-ku, Tokyo 152-8552, Japan \\ (Received October 11, 2016; accepted December 26, 2016)
}

Keywords: diamond-like carbon, corrosion, sodium hydroxide solution, silicon, pinhole

Chemical resistance to high concentrations of sodium hydroxide solutions on diamond-like carbon (DLC) films was investigated by immersion testing. DLC films were deposited on silicon (Si) and polytetrafluorethlene (PTFE) plates. These sample were put into a 17 at.\% sodium hydroxide solution. The DLC films on PTFE were maintained for $48 \mathrm{~h}$, although most of the DLC films deposited on $\mathrm{Si}$ were removed. To understand this reaction, the results of immersion tests using $10 \mathrm{wt} . \%$ sodium hydroxide solution were observed in situ. Many bubbles appeared after $14 \mathrm{~h}$. The number of the bubbles, which were reaction points, increased with the duration of the immersion test. We observed areas where the DLC film remained, and these places experienced no change. DLC films were peeled away because of the corrosion of the Si substrate by the sodium hydroxide. These bubbles were probably hydrogen gas, which results from the reaction between silicon and sodium hydroxide. Hence, the DLC films contained weak points against sodium hydroxide solution, or there were extremely small through holes in the DLC film.

\section{Introduction}

Diamond-like carbon (DLC) films are hydrogenated amorphous carbon $(a-\mathrm{C}: \mathrm{H})$ films; they have been applied to mechanical parts owing to their high hardness and low friction coefficient. ${ }^{(1-3)}$ These films consist of carbon and hydrogen atoms; the carbon atoms are mainly $s p^{2}$ - or $s p^{3}$ hybridized.

Due to the structural flexibility of $s p^{2}$ - and $s p^{3}$-hybridized carbon atoms, these films are all referred to as "DLC" although their properties depend on the arrangement of the $s p^{2}$ - and $s p^{3}$ hybridized carbon atoms. To indicate the film structure, a tertiary diagram consisting of the content $s p^{2}$ and $s p^{3}$ carbon atoms and hydrogen atoms was proposed by Robertson. ${ }^{(4-6)}$ The relationships between the film properties and the structure of DLC films have often been discussed using this tertiary diagram. The relationship between the resistance and film structure of DLC films against some chemicals has been reported. ${ }^{(7-9)}$ Some reports indicate that the rate of film thickness change is very slow, such as sub-nanometers per hour. Sasaki et al. reported the etching rate of an $a-\mathrm{C}: \mathrm{H}$ film by nitric acid solution using the surface plasmon resonance (SPR). ${ }^{(10)}$ The chemical resistance of an $a-\mathrm{C}: \mathrm{H}$ film can be quantitatively estimated using their method, and the

${ }^{*}$ Corresponding author: e-mail: akasaka@mech.titech.ac.jp

http://dx.doi.org/10.18494/SAM.2017.1482 
etching rate was determined to be less than $2.5 \mathrm{~nm} / \mathrm{h}$. Hence, it is currently believed that DLC films have high chemical resistance.

On the other hand, these reports indicated only the resistance to chemical solutions at low concentration. ${ }^{(8-13)}$ As it is important to apply chemical resistant coatings, for example, at chemical plants, chemical resistance against solutions of high concentration is an important property to assess. Typically, a highly concentrated sodium hydroxide solution is used at many chemical plants in electrolysis to obtain hydrogen and oxygen gases and for the saponification of fatty acids. Previous reports about DLC films exposed to sodium hydroxide involved solutions of low concentration. Some reports also indicated that DLC films have pinholes. ${ }^{(14-16)}$ These holes or pores may affect chemical corrosion by solutions of high concentration. Hence, corrosion of DLC films by highly concentrated sodium hydroxide solutions was investigated. In this paper, we report the estimation of corrosion by immersion testing of DLC films with respect to sodium hydroxide solutions of $10 \mathrm{wt} . \%$ or higher concentrations.

\section{Experimental Method}

Silicon (100) and polytetrafluorethlene (PTFE) were used as substrates. DLC films were synthesized using pulsed plasma enhanced chemical vapor deposition (PECVD). ${ }^{(17)}$ Before deposition, the oxidation layer at the $\mathrm{Si}(100)$ surface was removed by argon ion irradiation. To insure sufficient adhesion to the substrate, the hydrogenated amorphous silicon carbide layer was deposited between the DLC film and the substrate. Tetramethylsilane (TMS) at a flow rate of 15 $\mathrm{cm}^{3} /$ min was used as the source of the hydrogenated amorphous silicon carbide layer. A pulsed bias voltage of $-4.5 \mathrm{kV}$ with a frequency of $14.4 \mathrm{kHz}$ was applied to the substrate. Deposition duration was $30 \mathrm{~min}$ for the interlayer. To deposit DLC films, acetylene gas at a flow rate of 20

$\mathrm{cm}^{3} /$ min was used as the carbon source. A pulsed bias voltage of $-4.5 \mathrm{kV}$ with a frequency of 14.4 $\mathrm{kHz}$ was applied to the substrate. The thickness of the the deposited film for the DLC layer was approximately $1.5 \mu \mathrm{m}$. Previous work had established that the DLC film contained $66.9 \% s p^{2} /\left(s p^{2}\right.$ $+s p^{3}$ ) carbon and 17 at.\% hydrogen. ${ }^{(9)}$

Sodium hydroxide solution with a concentration of $17 \mathrm{wt} . \%$ was prepared for the corrosion test. A $10 \mathrm{wt} . \%$ sodium hydroxide solution was also prepared for the in-situ observation of corrosion. Although we tried to use higher concentration solutions, the corrosion rate was too high for these observations. Each solution was adjusted to the desired concentration using 5.0 or $8.5 \mathrm{~g}$ sodium hydroxide (Wako Chemical Industries) and $200 \mathrm{ml}$ pure deionized water. Each solution was cooled to room temperature after the increase in temperature due to the heat of dissolution.

The procedure for investigating corrosion was as follows. First, a $17 \mathrm{wt} \%$ sodium hydroxide solution was poured into PTFE dishes. DLC films deposited on Si and PTFE were put in at the same time. After 12, 24, and $48 \mathrm{~h}$, the sample of DLC deposited on Si(100) was partially removed using a diamond cutter. Samples of the deposited on PTFE and Si(100) were picked up from solution after $48 \mathrm{~h}$. Surface images before and after the test were obtained using an optical microscope and an atomic force microscope (AFM; SPA300, Seiko Instruments). For the in situ observation, a microscope movie system was used. Once the movie was recoreded, the DLC film deposited on $\mathrm{Si}(100)$ was put into a dish with a $10 \mathrm{wt} . \%$ sodium hydroxide solution. 


\section{Results and Discussions}

The appearance of the film surface before and after $12 \mathrm{~h}$ of corrosion testing in the highly concentrated solution of sodium hydroxide solution (17 wt.\%) was obtained and is shown in Fig. 1. After $12 \mathrm{~h}$, some pores were observed at some sites on the sample deposited on $\operatorname{Si}(100)$, although no changes were noted on the DLC film deposited on PTFE. After $24 \mathrm{~h}$, the DLC film at most places deposited on the $\mathrm{Si}(100)$ substrate had disappeared, where the DLC film deposited on PTFE evidenced no change. To understand the microstructural changes, images of the film surfaces before and after testing were obtained using a microscope. Figure 2 shows photomicrographs of the sample surface of DLC films deposited on $\mathrm{Si}(100)$ before and after 12 and $24 \mathrm{~h}$ of exposure. The surface before the test was smooth and mirror-like. After $12 \mathrm{~h}$ of exposure, the film surface displayed many pores $50 \mu \mathrm{m}$ in diameter. These pores appeared to be square. After $24 \mathrm{~h}$, the pores had grown and the number of pores had also increased. After $48 \mathrm{~h}$, no DLC films were left on $\mathrm{Si}(100)$. On the other hand, DLC films on PTFE showed no change after $48 \mathrm{~h}$ of corrosion testing, as shown in Fig. 3.

To understand the microstructural changes, AFM images were taken before and after corrosion tests, as shown in Fig. 4. Areas inside the pores and near the pores were hard to observe by AFM because the roughness in these area was too high to observe with this method. Therefore, we obtained surface images at the areas where DLC remained. The ten-point average surface roughness, $R_{z}$, of the sample surface changed from 22.5 to $44.5 \mathrm{~nm}$ as a result of the corrosion test after $12 \mathrm{~h}$. The value of $R_{z}$ was $16.9 \mathrm{~nm}$ after $24 \mathrm{~h}$. The mean of roughness value, $R_{a}$, of the sample surface was $2.0,2.8$, and $1.5 \mathrm{~nm}$ for before samples, and at 12 and $24 \mathrm{~h}$ after corrosion testing, respectively. The main reason for the destruction of DLC films was not the corrosion of DLC films, because DLC films on PTFE were maintained after $48 \mathrm{~h}$ of the testing. These results suggest that the pores are the result of partial pitting corrosion, and that the sodium hydroxide solution reached the $\mathrm{Si}$ substrate through these holes. It is likely that $\mathrm{Si}$ was etched by the sodium hydroxide solution ${ }^{(18)}$ and the DLC films were destroyed by the etching of the Si substrate.

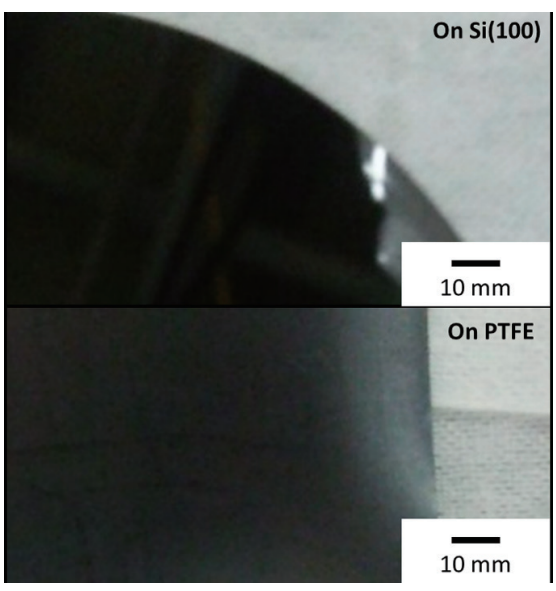

(a)

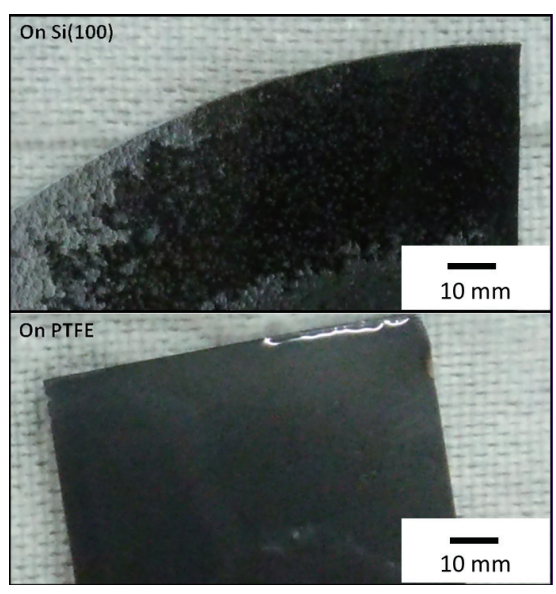

(b)

Fig. 1. (Color online) Appearance before and after $12 \mathrm{~h}$ of exposure: (a) initial and (b) after $12 \mathrm{~h}$. 
(a)

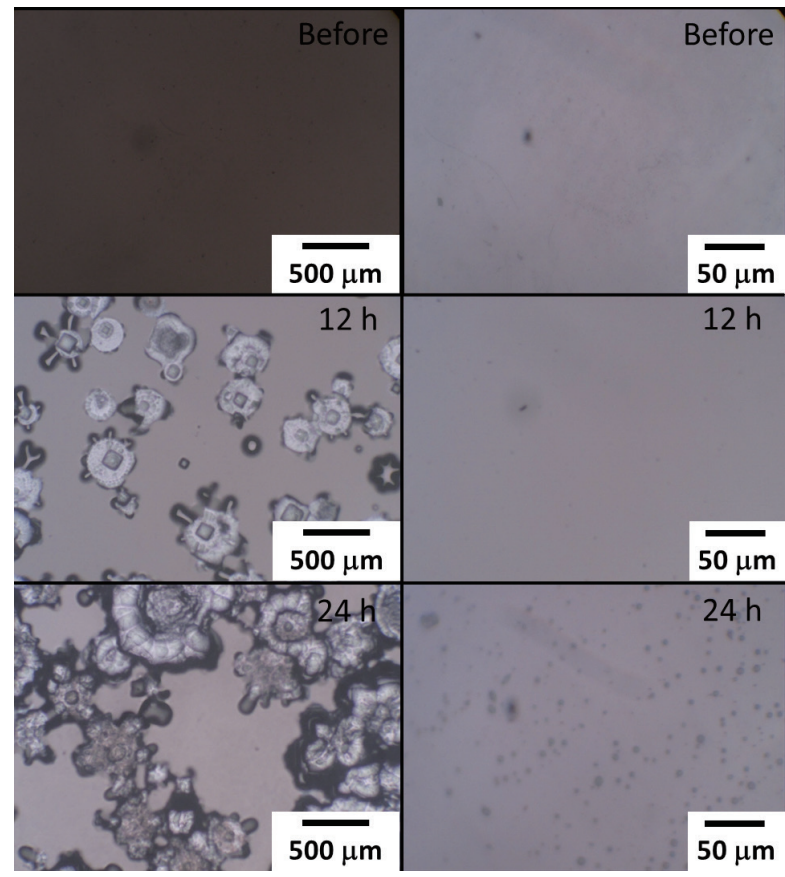

Fig. 2. (Color online) Photomicrographs of the surface of DLC films deposited on $\mathrm{Si}(100)$ (a) before, after (b) 12 , and (c) $24 \mathrm{~h}$ of exposere.

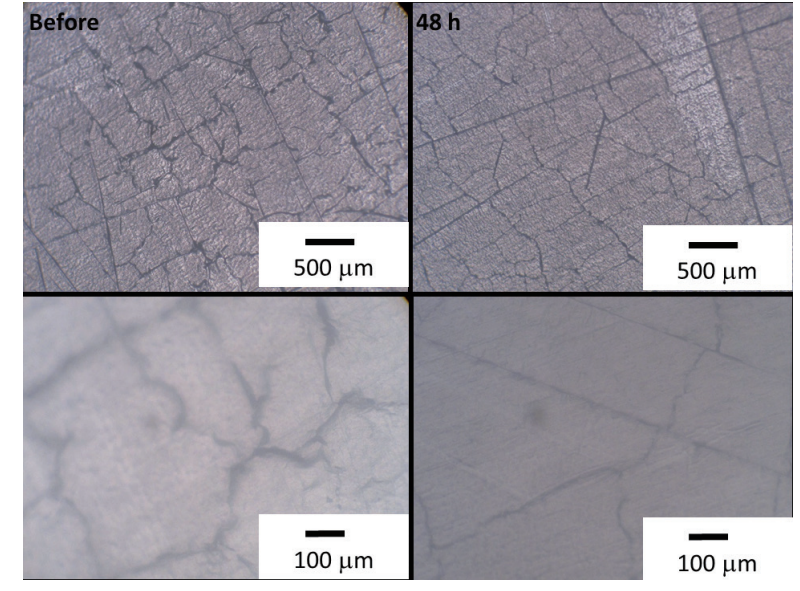

(a)

(b)

Fig. 3. (Color online) Photomicrographs of the surface of DLC films deposited on PTFE (a) before and (b) after $48 \mathrm{~h}$ exposure.
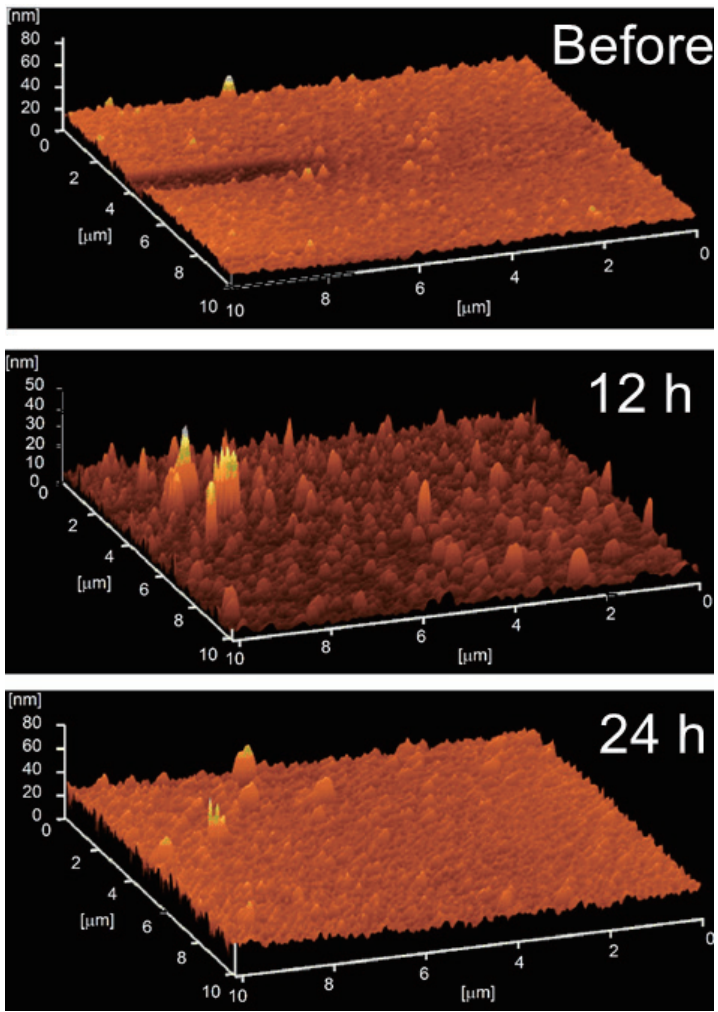

Fig. 4. (Color online) AFM images before and after corrosion tests. 
If partial corrosions is the main reason for the pores, the reaction sites on the surface may generate bubbles of reactive $\mathrm{H}_{2}$ caused by the following reaction between $\mathrm{Si}$ and sodium hydroxide solution:

$$
\mathrm{Si}+2 \mathrm{NaOH}+\mathrm{H}_{2} \mathrm{O} \rightarrow \mathrm{Na}_{2} \mathrm{SiO}_{3}+2 \mathrm{H}_{2} \uparrow
$$

Thus, the in situ observation of corrosion of DLC films on $\mathrm{Si}(100)$ was investigated. Figure 5 shows surface images of DLC films deposited on $\mathrm{Si}(100)$ at $4 \mathrm{~h}$ increments during corrosion testing. These images revealed no changes during $16 \mathrm{~h}$. A few sites shows the evolution of microbubbles after $20 \mathrm{~h}$, and the number of bubbles increased with time. After $28 \mathrm{~h}$, the number of sites generating bubbles rapidly increased. These bubbles were also generated on the non-coated side, because the silicon was easily corroded by sodium hydroxide solution. Hence, these bubbles are caused by the reaction between the silicon substrate and the sodium hydroxide solution.

Some reports have indicated that DLC films contain extremely small pores, such as nano- or micropores. It is difficult to consider that these pores are submicron-order through holes, because the duration of bubbling was at least $14 \mathrm{~h}$. Although chemical resistance is very weak, lacking resistance to sodium hydroxide solutions still have some resistance to reaction. When the $\mathrm{Si}$ substrate was put into a sodium hydroxide solution, we observed corrosion in less than $2 \mathrm{~h}$. Hence,
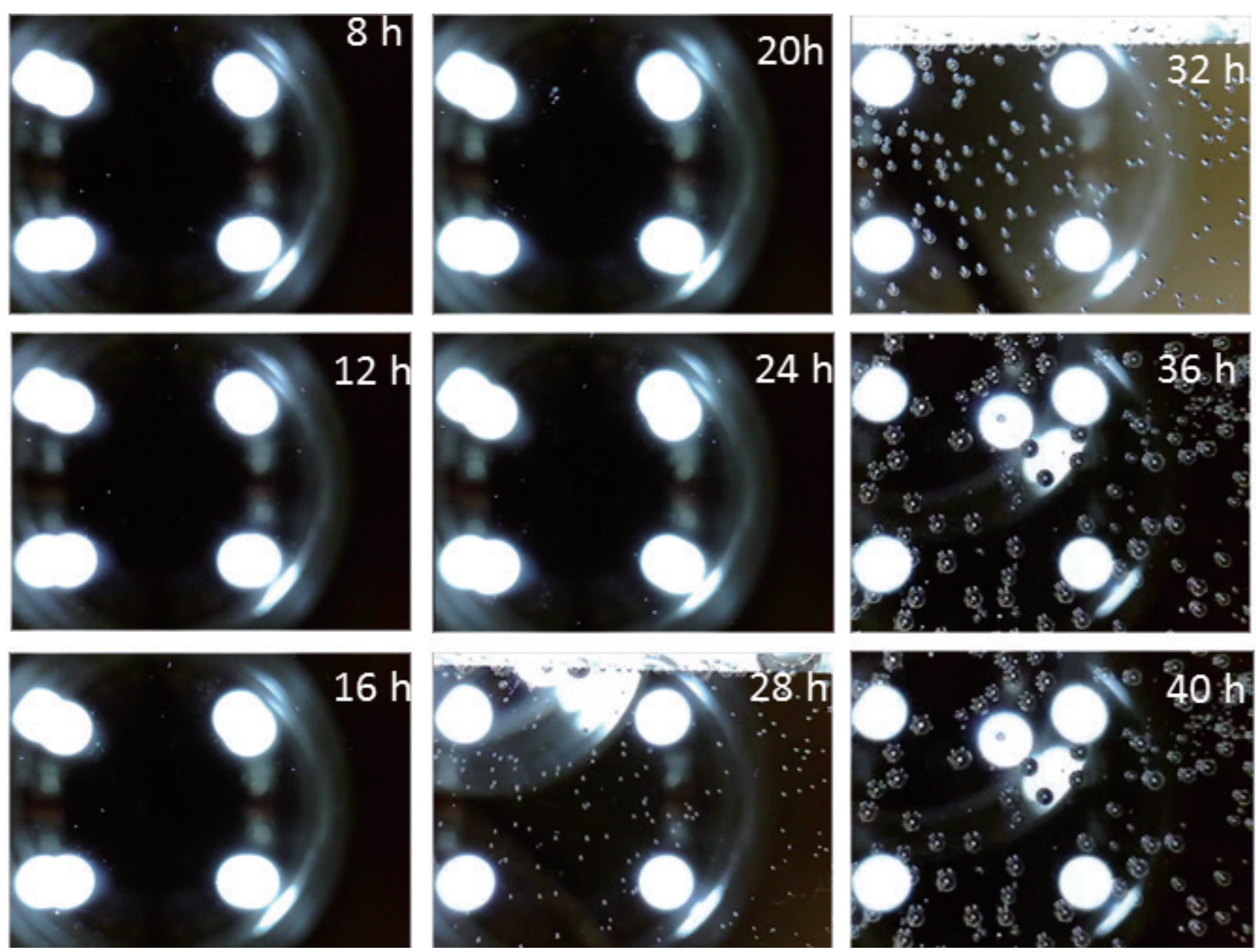

Fig. 5. (Color online) Photomicrographs obtained during in situ observation of corrosion of DLC films on $\operatorname{Si}(100)$. 
$14 \mathrm{~h}$ is too long to see no corrosion at all. From the theoretical molecular size in the test solution, the pore size may be less than $1 \mu \mathrm{m}$. Thus, two phenomena must be considered regarding the pitting corrosion. Furthermore, we cannot deny the possibility that these holes are not open but are closed pores. When those pinholes are closed by thin layers, the duration of corrosion by a nitric acid solution on the Si substrate may be equal to corrosion duration. We now do not have a reason why the time required to reach $\mathrm{Si}$ was not as short as a few minutes. These results suggest that DLC contained some sites with weak resistance against sodium hydroxide solutions or that there were extremely small through holes in the DLC film.

\section{Conclusions}

Immersion testing for DLC films with sodium hydroxide solutions of high concentration was carried out. From a comparison of two substrates, Si and PTFE, DLC films on PTFE were maintained for $48 \mathrm{~h}$, while most of the DLC films deposited on Si peeled off. The DLC films were peeled by the corrosion of the Si substrate due to the reaction between sodium hydroxide and silicon, because many square pits were observed on Si after the test. In situ observation of the corrosion revealed the appearance of many bubbles after $14 \mathrm{~h}$. These bubbles were probably hydrogen gas, which resulted from the reaction between silicon and sodium hydroxide. Hence, DLC contained weak sites where reaction with sodium hydroxide solution took place, or there may have been extremely small through holes in the DLC film. In this study, DLC films on two types of substrates were investigated, and there may also be different stresses between the films and substrates.

Further studies are needed to understand the chemical corrosion on DLC in terms of compressive stresses in the film. Compressive stress in the DLC films may affect the chemical resistance. This knowledge may improve the use of DLC films for applications as chemical resistant coatings.

\section{Acknowledgments}

This work was supported by JSPS KAKENHI Grant Number 15K18038, Mitutoyo Association for Science and Technology, and The Moritani Scholarship Foundation.

\section{References}

1 M. Hiratsuka, H. Nakamori, Y. Kogo, M. Sakurai, N. Ohtake, and H. Saitoh: J. Solid Mech. Mater. Eng. 7 (2013) 187.

2 A. Vanhulsel, F. Velasco, R. Jacobs, L. Eersels, D. Havermans, E. W. Roberts, I. Sherrington, M. J. Anderson, and L. Gaillard: Tribo. Int. 40 (2007) 1186.

3 E. L. Dalibon, R. Charadia, A. Cabo, V. Trava-Airoldi, and S. P. Brühl: Surf. Coat. Techol. 235 (2013) 735.

4 J. Robertson: Mater. Sci. Eng. R 37 (2002) 129.

5 A. Grill: Dia. Relat. Mater. 8 (1999) 428.

6 J. Robertson: J. Non-Crystal. Solids 164-166 (1993) 1115.

7 B. Tomcika, T. Osipowicz, and J.Y. Lee: Thin Solid Films 360 (2000) 173.

8 L. J. Yu, D. Sheeja, B. K. Tay, Daniel H. C. Chua, W. I. Milne, J. Miao, and Y. Q. Fu: Appl. Surf. Sci. 195 (2002) 107.

9 A. Takarada, T. Suzuki, K. Kanda, M. Niibe, M. Nakano, N. Ohtake, and H. Akasaka: Dia. Relat. Mater. 51 (2014) 49. 
10 Y. Sasaki, A. Takeda, K. Ii, S. Ohshio, H. Akasaka, M. Nakano, and H. Saitoh: Dia. Relat. Mater. 24 (2012). 104.

11 H. Miya and J. Wang: Mater. Trans. 49 (2008) 1333.

12 M. A. S. Oliveira, M. Massi, L. N. Nishioka, G. P. Thim, R. W. Bartar, and A. K. Vieira: J. New Mater. Electrochem. Syst. 5 (2002) 67.

13 M. Cui, J. Pu, G. Zhang, L. Wang, and Q. Xue: Royal Soc. Chem. Adv. 6 (2016) 28570.

14 M. Yatsuzuka, J. Tateiwa, and H. Uchida: Vacuum 80 (2006) 1351.

15 A. Herrera-Gomez, F. S. Aguirre-Tostado, Y. Sun, R. Contreras-Guerrero, R. M. Wallace, Y. Hisao, and E. Flint: Surf. Interface Anal. 39 (2007) 904.

16 R. P. O. S. Nery, R. S. Bonelli, and S. S. Camargo, Jr.: J. Mater. Sci. 45 (2010) 5472.

17 S. Fujimoto, N. Ohtake, and O. Takai: Surf. Coat. Technol. 206 (2011) 1011.

18 C. Lai, X. Li, D. Zhang, Z. Xiang, W. Yang, and X. Guo: Mater. Chem. Phys. 144 (2014) 355. 